\title{
The Future Climate Moisture Susceptibility of Wall Assemblies: Analysis Based on Monte Carlo Simulation Using a Simplified Deterministic Hygrothermal Simulation Model
}

\author{
Carl-Eric Hagentoft ${ }^{1}$ and Pär Johansson ${ }^{1}$ \\ ${ }^{1}$ Chalmers University of Technology, Department of Architecture and Civil Engineering, \\ SE-41296 Göteborg, Sweden, carl-eric.hagentoft@chalmers.se
}

\begin{abstract}
A newly developed generic algorithm to assess moisture susceptibility of simplified wall assemblies has been developed within the CIB-W080 WG 2. This group is focusing on guidelines for design for durability of building envelopes. The algorithm is implemented in a publicly available Matlab code. A simplified wall assembly consisting of up to four material elements is considered. Optional vapor retarder and thermal resistances are located between the elements. In this paper modelling of a ventilated cladding is implemented. Using the simplified numerical model, a probability-based risk analysis using the Monte Carlo method is demonstrated. The risk assessment of the wall assembly considers the interior and exterior climatic load. The moisture transport mechanism accounted for in the analysis is diffusion. The rain load is assumed to be transferred directly to a chosen outer susceptible material element in the construction. An insulated wooden wall structure is analyzed and the probability distribution of the time of wetness is presented for cases using sequence of 31 consecutive climatic years, randomly varying indoor moisture excess, indoor temperature and driving rain leakages.
\end{abstract}

Keywords: Climate, Driving Rain, Simplified Model, Risk Analysis, Monte Carlo Simulation.

\section{Introduction}

The performances of buildings can vary quite a lot even if the design look identical in the drawings. The uncertainties are manifold and originate from the selection of the initial condition of materials, dimensions, and material properties. Also, the operation of the building causes uncertainties originating from the actual indoor moisture excess, internal heat gains, air infiltration, and ventilation. Obviously, weather conditions and the exposure to the external environment are also sources of uncertainties; this is illustrated in Figure 1. Because of all the uncertainties and possible variations, the total life cycle cost for the operation and maintenance of a stock of buildings will vary randomly due to the spread in factors such as initial investment, energy use, hygrothermal performances, and performance failures. To make balanced and sound choices of design strategies and investment decisions, all these factors should be included. The results from the IEA EBC project RAP-RETRO (Annex 55) (Hagentoft, 2017; Bednar and Hagentoft, 2015; Hagentoft et al., 2015a; 2015b; 2015c; 2015d) are intended to improve methods and tools for the integrated evaluation and optimization of retrofitting measures, including energy efficiency, life cycle cost, and durability. 


\section{Probabilistic approach}

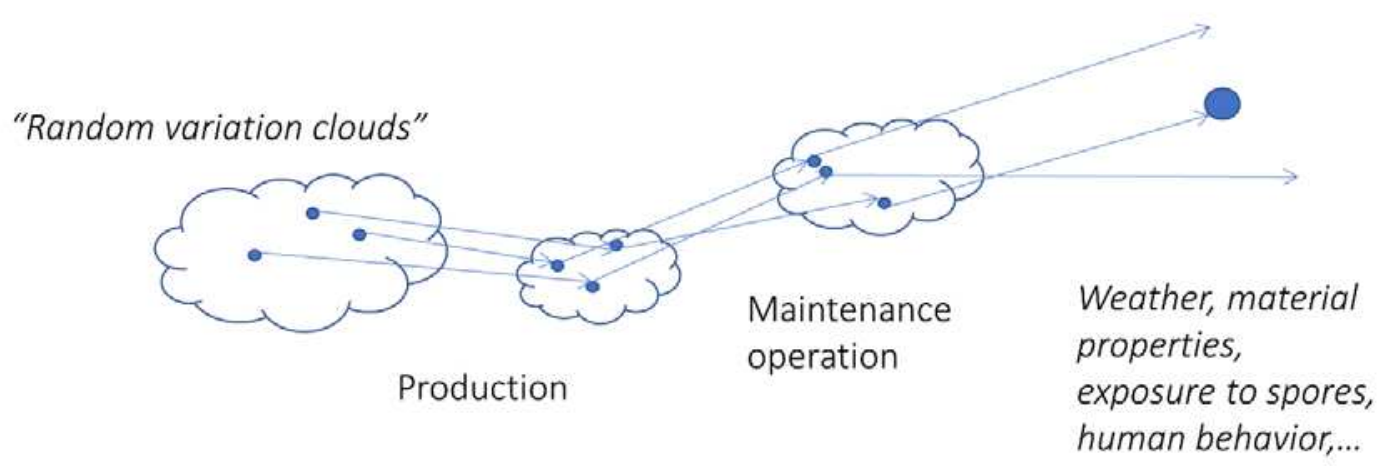

Examples of

random variations in:

Indoor moisture sources, internal gains

airing, aging of material,

Workmanship

cracks in façades,...

initial conditions of material,...

Figure 1. Random variation of cloud type representing variability and uncertainties.

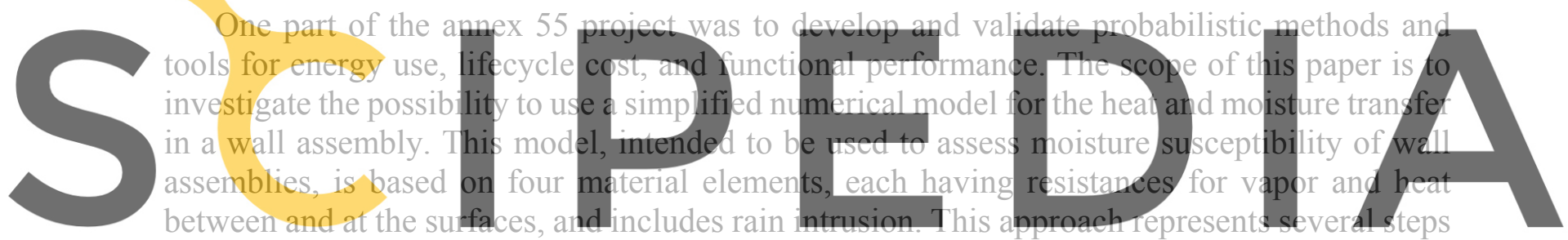

forward in terms of precision compared with the older and more traditional Glaser method and

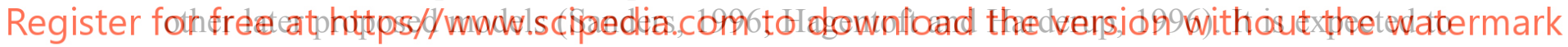

be well in line with modern detailed moisture calculation models. With the proposed model, a

probabilistic assessment of the risk for failure of various performances such as time of wetness, mould growth, and heat loss can be investigated. Also, sensitivity analysis can be performed on different calculation parameters.

The mathematics of the model is explained in detail (Hagentoft and Johansson, 2019) and can be implemented on various platforms such as Matlab or Python.

This work is a part of CIB W080, WG2, for the guidelines on design for durability of building envelopes for use by engineers and designers who are unlikely to have tools at their disposal to determine model inputs. It will provide background knowledge for hygrothermal simulations and long term durability risk assessments considering climate change. Within this work, the National Research Council (Conseil national de recherches Canada), NRC, provides climate data sets for historic and future scenarios. 


\section{Case Study}

The investigated construction in this paper is an insulated wooden wall with an exterior air gap, see Figure 2. The insulation layer, outside the wooden layer, has a thickness of $300 \mathrm{~mm}$ and a thermal conductivity of $0.033 \mathrm{~W} /(\mathrm{m} \cdot \mathrm{K})$ while the wooden boards are $128 \mathrm{~mm}$ thick with a thermal conductivity of $0.14 \mathrm{~W} /(\mathrm{m} \cdot \mathrm{K})$. The material properties for the insulation and the wood are presented in Table 1 and Table 2.

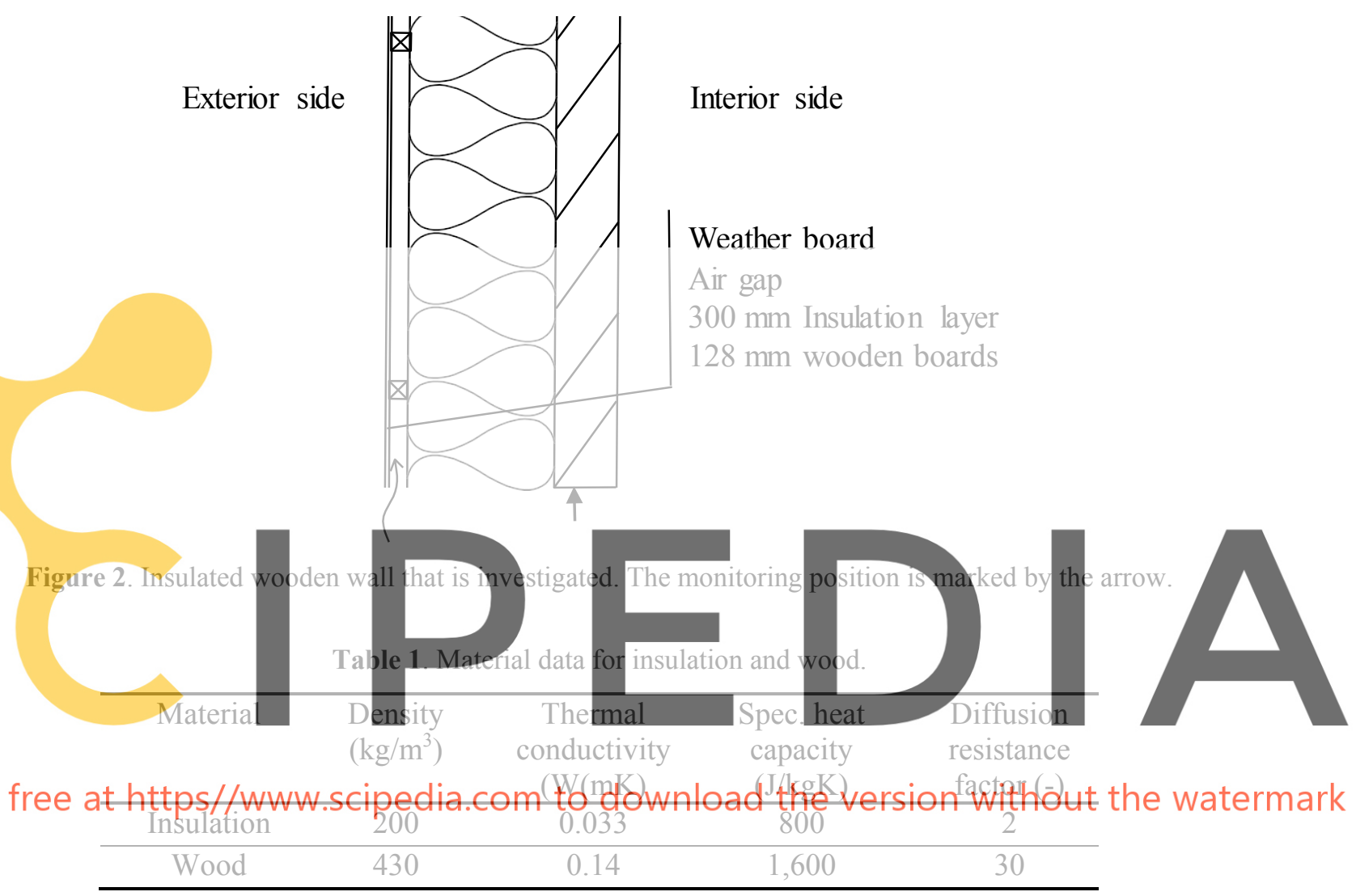

Table 2. Moisture sorption isotherms.

\begin{tabular}{ccc}
\hline $\begin{array}{c}\text { Relative } \\
\text { humidity }\end{array}$ & $\begin{array}{c}\text { Insulation } \\
\left(\mathrm{kg} / \mathrm{m}^{3}\right)\end{array}$ & $\begin{array}{c}\text { Wood } \\
\left(\mathrm{kg} / \mathrm{m}^{3}\right)\end{array}$ \\
\hline 0 & 0 & 0 \\
\hline 35 & 0.25 & 37.5 \\
\hline 50 & 0.40 & 47.5 \\
\hline 70 & 0.47 & 65.0 \\
\hline 80 & 0.53 & 77.5 \\
\hline 90 & 0.60 & 100 \\
\hline 95 & 1.0 & 117.5 \\
\hline 99.9 & 10 & 140 \\
\hline 100 & 100 & 1000 \\
\hline
\end{tabular}




\section{Weather Data}

The historical and future climate data for the Canadian cities Toronto and Vancouver, see Table 3 , were selected. The data was provided by (Gaur et al., 2019) who produced time-series of 30 consecutive years with hourly climate data corresponding to historical time-period (1986-2016) and future time-series corresponding to $2^{\circ} \mathrm{C}$ and $3.5^{\circ} \mathrm{C}$ increase in global temperature. In this paper the former climate scenario was selected.

Table 3. Data for Toronto and Vancouver.

\begin{tabular}{ccccc}
\hline City & $\begin{array}{c}\text { Latitude } \\
\left({ }^{\circ} \mathrm{C}\right)\end{array}$ & $\begin{array}{c}\text { Longitude } \\
\left({ }^{\circ} \mathrm{E}\right)\end{array}$ & $\begin{array}{c}\text { Population } \\
\text { in } 2016 \\
(1000 \mathrm{~s})\end{array}$ & Climate zone \\
\hline Toronto & 43.7 & -79.4 & 3731.6 & $\begin{array}{c}\text { Great lakes/St. } \\
\text { Lawrence lowlands }\end{array}$ \\
\hline Vancouver & 49.3 & -123.1 & 2463.4 & $\begin{array}{c}\text { Pacific coast/South } \\
\text { British Columbia } \\
\end{array}$ \\
& & & & Mountains \\
\hline
\end{tabular}

\subsection{Driving Rain Model}

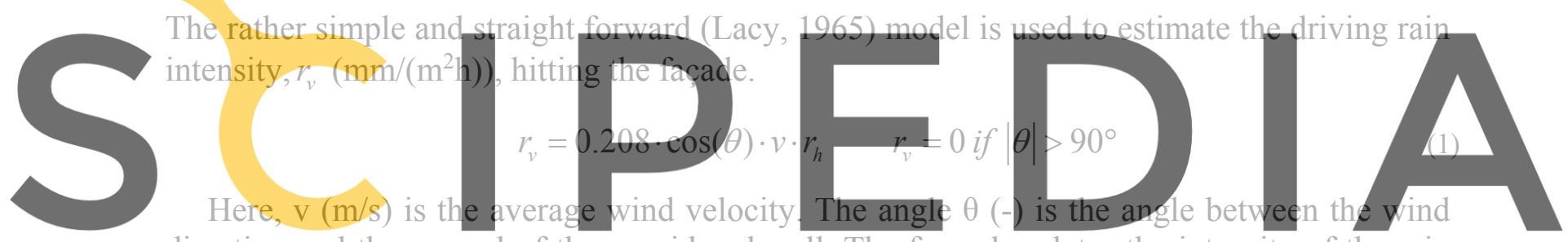

direction and the normal of the considered wall. The formula relates the intensity of the rain

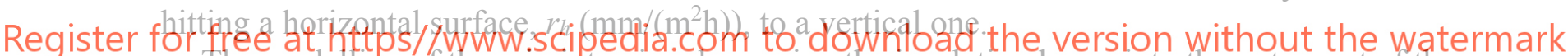
The modelling of the rain intrusion, bypassing the insulation layer, into the outer part of the wood, is based on 1\% of the driving rain intensity. The leakage is based on a uniform random distribution, meaning that only one tenth of the rain events result in leakage corresponding to an intensity of $1 \%$ of the actual driving rain at that event. Table 4 presents the direction dependent driving rain intensity in each 30 -year period in Toronto and Vancouver.

Table 4. Toronto and Vancouver driving rain intensity, the total summation of each 30 -year period $\left(\right.$ tonnes $\left./ \mathrm{m}^{2}\right)$.

\begin{tabular}{ccccc}
\hline Direction & $\begin{array}{c}\text { Toronto } \\
\text { (historica } \\
1)\end{array}$ & $\begin{array}{c}\text { Toronto } \\
\left(+2^{\circ} \mathrm{C}\right)\end{array}$ & $\begin{array}{c}\text { Vancouver } \\
(\text { historical })\end{array}$ & $\begin{array}{c}\text { Vancouver } \\
\left(+2{ }^{\circ} \mathrm{C}\right)\end{array}$ \\
\hline North & 6.64 & 7.97 & 1.19 & 1.61 \\
\hline East & 7.68 & 9.41 & 18.5 & 19.9 \\
\hline South & 9.15 & 8.65 & 26.5 & 26.8 \\
\hline West & 7.09 & 6.25 & 4.32 & 4.53 \\
\hline
\end{tabular}

The calculations show that direction South was the dominant direction for driving rain in Toronto, but in the future, this will change to East. In Vancouver, South is the dominant 
direction for driving rain, both historically and in the future. In this study, for simplicity, only main compass directions were used and a South facing façade was chosen for both cities and for all the climate time-series.

\subsection{Solar Radiation}

Direct solar radiation and diffuse solar radiation on a vertical surface was given in the climate files. This was recalculated to hourly solar radiation for an inclined surface facing South based on angle of incidence, horizontal shadow angle and vertical shadow angle on inclined surface evaluated in middle of hour from reference year with hourly radiation data (Duffie and Beckman, 1991). The albedo of the ground was assumed to be 0.2 .

\section{Simulation Model}

In the simplified model, a wall assembly consisting of four material elements is considered. Optional thin elements (zero thickness) with heat and vapor resistances are included in the model that for instance can be used for the representation of a vapor retarder. The risk assessment of the wall assembly considers the interior and exterior climates. The use of an equivalent external temperature permits consideration not only of the air temperature, but also of the effects of the long- and short-wave radiation. A prescribed driving rain intrusion function must be included that accounts for the effect of water leakage to the interior of the wall assembly. Prescribed outdoor and indoor water vapor concentrations are assumed where the moisture transport mechanism accounte for in the analysis is diffusion. The heat transfer is based on heat conducti transfer is assumed to $b$

The moisture transfe relative humidity in the
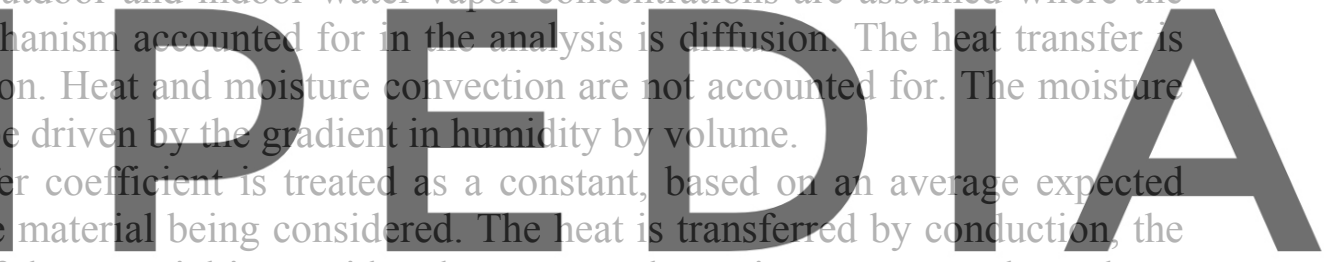

thermal conductivity of the material is considered constant. The moisture content depends on

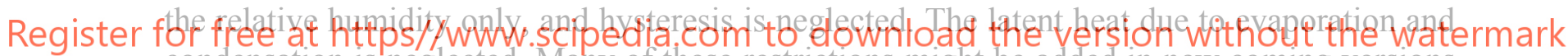
condensation is neglected. Many of these restrictions might be added in new coming versions of the model.

\subsection{Ventilated Cavity}

The following parameters are of importance: $R_{\text {out }}, R_{a}, \alpha_{c, c d}, \alpha_{r}, Z_{\text {cladding }}$. They are the total thermal resistance from the interior cladding surface to the outdoors including external surface resistance, air flow rate of the gap behind the cladding, the combined conductive and convective heat transfer coefficient of the air gap, the radiant heat transfer coefficient across the air gap, and finally the total vapor resistance of the cladding.

$$
\begin{aligned}
& \alpha_{c}=2 \cdot \alpha_{c, c d} \\
& \alpha_{r}=4 \varepsilon_{12} \sigma T^{3} \quad 1 / \varepsilon_{12}=1 / \varepsilon_{1}+1 / \varepsilon_{2}-1
\end{aligned}
$$

In the last formula the emissivity of the surfaces surrounding the air gap is used together with the Stefan-Boltzmann constant. The temperature is in Kelvin.

Network analysis (Hagentoft, 2001) is used to reduce it all to effective resistances and external temperatures. The following expressions for the resistance of the analyzed structure to 
the external environment is used, and replaces those used in (Hagentoft and Johansson, 2019):

$$
R_{0}=\frac{1}{K_{a}+K_{b}}+\frac{1}{K_{2}}, Z_{0}=\frac{1}{R_{a}+1 / Z_{\text {cladding }}}, T_{\text {out } \text { new }}^{\text {eq }}=\frac{K_{a} \cdot T^{e q}+K_{b} \cdot T_{\text {out }}}{K_{a}+K_{b}}
$$

The humidity by volume, $v_{\text {out }}\left(\mathrm{kg} / \mathrm{m}^{3}\right)$, used in the model remains the same. The following parameters are used in the expression.

$$
\begin{aligned}
& K_{a}=\frac{1}{R_{\text {out }}+1 / K_{1}} \quad K_{b}=\frac{1}{1 /\left(R_{a} \cdot \rho c_{p a}\right)+1 / K_{3}} \\
& K_{1}=K_{2}=\frac{\alpha_{r} \cdot \alpha_{c}}{\tilde{K}} \quad K_{3}=\frac{\alpha_{c}^{2}}{\tilde{K}} \quad \tilde{K}=\frac{1}{2 / \alpha_{c}+1 / \alpha_{r}}
\end{aligned}
$$

Here, the volumetric heat capacity of air, $\rho c_{p a}\left(\mathrm{~J} /\left(\mathrm{m}^{3} \mathrm{~K}\right)\right)$, at atmospheric pressure is used.

\subsection{Indoor Climate}

In respect to the indoor conditions, the indoor temperature was varied around $20^{\circ} \mathrm{C}$ with a normal distribution and standard deviation of $1.5^{\circ} \mathrm{C}$. The indoor moisture excess was always controlled to be greater than zero and varied with a normal distribution around $2 \mathrm{~g} / \mathrm{m}^{3}$ and standard deviation of $1 \mathrm{~g} / \mathrm{m}^{3}$.

\section{Results}

For simplicity in this study, the time of wetnes:

is the total time over th

construction. Based on
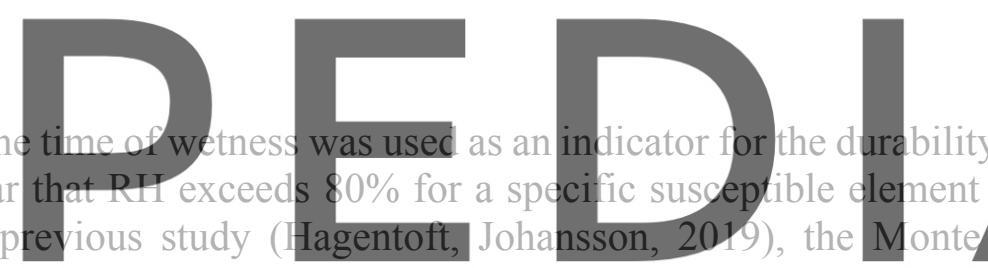

simulations are run for a total of 60031 -consecutive-year simulations using the simplified

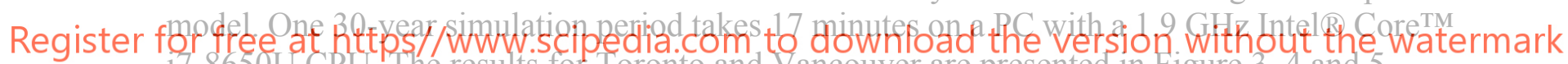
17-8650U CPU. The results for Toronto and Vancouver are presented in Figure 3 , 4 and 5.
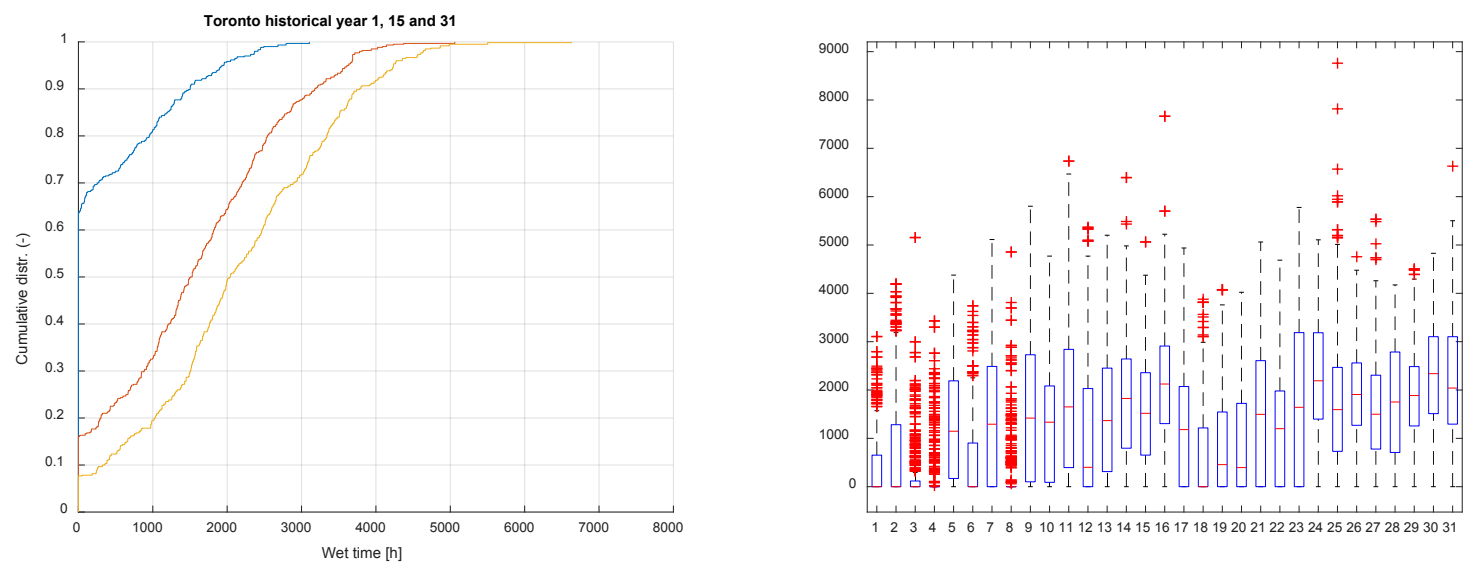

Figure 3. Results for the time of wetness for Toronto historical time-series.

There is a clear trend, visible both in the cumulative distribution and histogram, for Toronto 
that the time of wetness was increasing the last 30 years. The average time of wetness for year 1 was 392 hours, while it was 1566 and 2146 hours for year 15 and 31 respectively. The continuing trend can also be found in the future scenarios, where the time of wetness is 2611 hours the first year while it is 2899 and 3831 hours respectively for year 15 and 31.
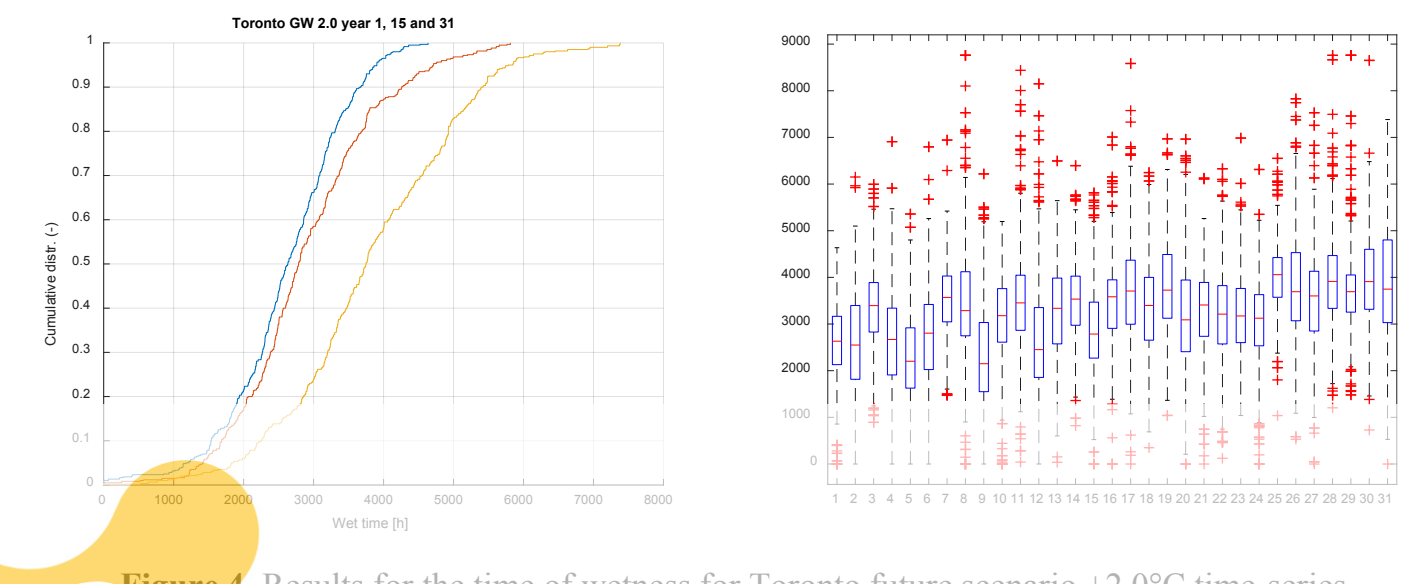

Figure 4. Results for the time of wetness for Toronto future scenario $+2.0^{\circ} \mathrm{C}$ time-series.
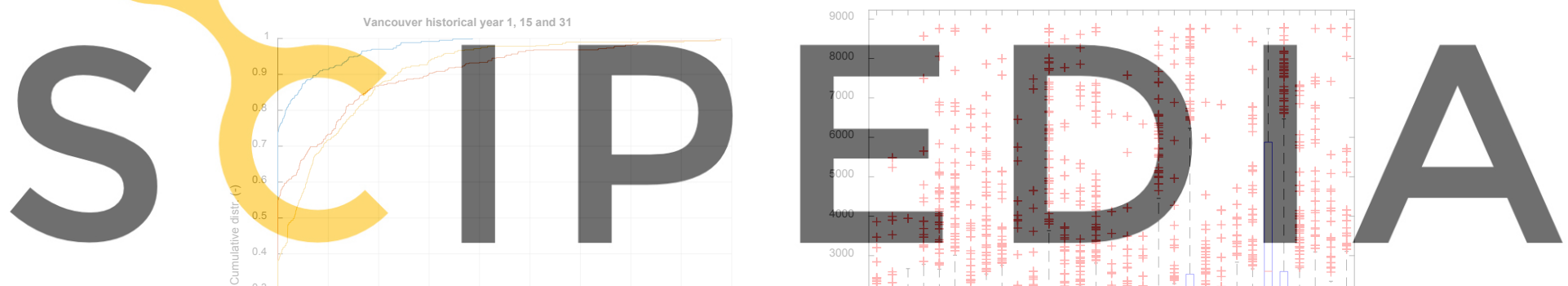

Register for free at https//www.scipedia.com to dowhilload the version without the watermark

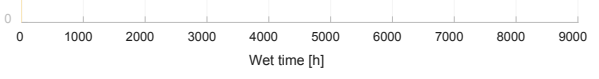

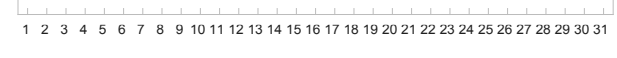

Figure 5. Results for the time of wetness for Vancouver historical time-series.

Also for Vancouver there is a clear trend in the cumulative distribution and histogram, that the time of wetness was increasing the last 30 years. The average time of wetness for year 1 was 219 hours, while it was 853 and 838 hours for year 15 and 31 respectively. It is also interesting to note the significantly larger number of outliers in Vancouver compared to in Toronto.

\section{Conclusions}

A previously developed simplified model for heat and mass transfer across walls, based on a four-element discretization of a wall assembly has been used in the paper. The simplified model offers good flexibility for representing multi-layer wall constructions with various barriers and 
for moisture and heat transfer in between layers. As such, it is suitable to be used for the risk assessment of wall assemblies and similar constructions. In this paper additions to the model are presented that make it possible to analyze structures with a ventilated cladding.

For the case presented in this paper, the impact of rain leakage on the outermost part of the external wood layer of an insulated wooden wall was demonstrated. The risk analysis is based on Monte Carlo simulations of 600 runs of 31-consecutive-year historical and future climate scenarios for Toronto and Vancouver. The expected time of wetness is 5 times higher in Toronto in 2016 compared to in 1986, and 1.5 times higher in 2064 compared to in 2034. In Vancouver the expected time of wetness is 4 times higher in 2016 compared to in 1986. However, for Toronto this may not be the most extreme case considering that south is not the predominant direction of wind driven rain in the future.

\section{ORCID}

C-E. Hagentoft: http://orcid.org/0000-0002-1616-3619

P. Johansson: http://orcid.org/0000-0003-0935-7703

References

Bednar, T. and Hagentoft, C.-E. (2015). IEA-EBC Annex 55. Reliability of energy efficient building retrofitting probability assessment of performance and cost (RAP-RETRO): risk management by probabilistic assessment. Development of guidelines for practice. Chalmers University of Technology, Gothenburg, Sweden.

Duffie, J.A. and Beckman, W. A. (1991). Solar Engineering of Thermal Processes. John Wiley \& Sons, 2. ed.

Gaur, A., Lacasse. M. and

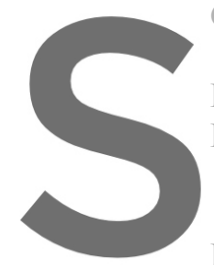
Simulations Under Projec

Hagentoft, C.-E. (2001). Intri

Hagentoft, C.-E. (2017). performance and cost 10.1016/j.enbuild.2017.0 . Climatio it
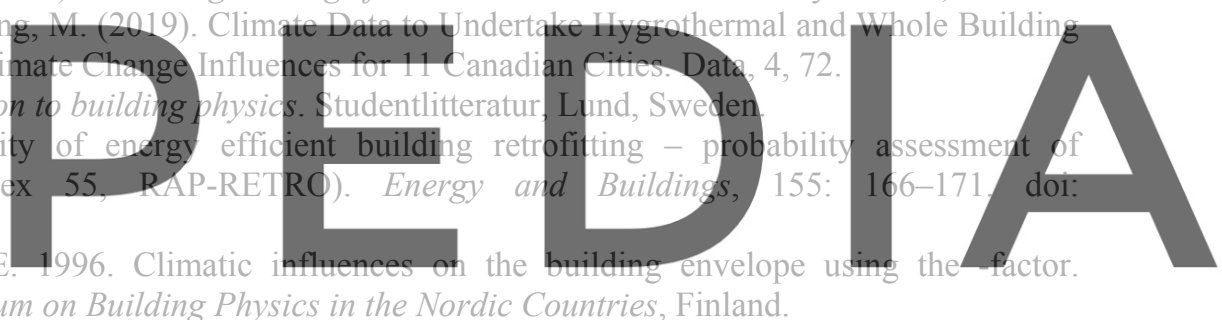
Proceedings of the 4th Symposium on Building Physics in the Nordic Countries, Finland.

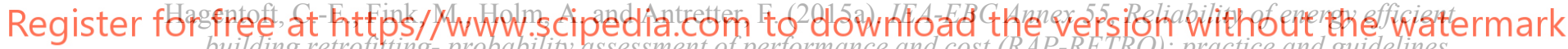
Chalmers University of Technology, Gothenburg, Sweden.

Hagentoft, C.-E., Janssen, H., Roels, S., Geider van, L. and Das, P. 2015b. IEA-EBC Annex 55, Reliability of energy efficient building retrofitting - probability assessment of performance and cost, (RAP-RETRO): probabilistic tools. Chalmers University of Technology, Gothenburg, Sweden.

Hagentoft, C.-E. and Johansson, P. (2019). Generic algorithm to assess moisture susceptibility of simplified wall assemblies. Canadian Journal of Civil Engineering, special issue Durability and Climate Change. doi: 10.1139/cjce-2018-0592.

Hagentoft, C.-E., Ramos, N. and Grunewald, J.(2015c). IEA-EBC Annex 55, Reliability of energy efficient building retrofitting - probability assessment of performance and cost, (RAP-RETRO): stochastic data. Chalmers University of Technology, Gothenburg, Sweden.

Hagentoft, C.-E., Sasic Kalagasidis, A. and Rode, C. (2015d). IEA-EBC Annex 55, Reliability of energy efficient building retrofitting - probability assessment of performance and cost (RAP-RETRO): framework for probabilistic assessment of performance of retrofitted building envelopes. Chalmers University of Technology, Gothenburg, Sweden.

Lacy, R.E. (1965). Driving-Rain Maps and the Onslaught of Rain on Buildings. Proceedings of RILEM/CIB Symposium on Moisture Problems in Buildings, Helsinki, Finland.

Sanders, C.H. (1996). IEA-EBC Annex 24, Design parameter used to avoid interstitial condensation for a range of climates: Task 2: environmental condition (HAMTIE). 